\title{
Was it Right New York Knicks Coach's Decision to Recruit a Point Guard?
}

\author{
Anggit Wicaksono ${ }^{1}$, Margono Margono ${ }^{2}$ \\ \{anggit_w@mail.unnes.ac.id ${ }^{1}$, margono@mail.unnes.ac.id ${ }^{2}$ \} \\ Universitas Negeri Semarang, Semarang, Indonesia ${ }^{12}$
}

\begin{abstract}
The aims of this study was to analyze New York Knicks Coach's decision in recruiting a point guard. In the 2019-2020 season, NY Knicks ended up in ranked 25 of 30 NBA teams. NY Knicks is ranked 29th for FG\% and 24th for 3PA and 3P\%. NY Knicks need a shooter to strengthen the team. But interestingly, the coach recruited a point guard. In the first 25 games in 2020-2021 season without this point guard, NY Knicks recorded 11 wins and 14 loses and is in 9th place on the eastern conference. In the next 25 games after new point guard joined, NY Knicks recorded 14 wins and 11 loses and is in 7th position. This means that NY Knicks' game has increased and has the potential for the playoffs. The research method uses descriptive quantitative. The data source is taken from the NBA official website.
\end{abstract}

Keywords: Basketball, New York Knicks, NBA

\section{Introduction}

Basketball is a game played by 2 teams with each team consisting of 5 players. The objective of each team is to score as many points as possible by putting the ball into the opponent's basket, and to prevent the opposing team from scoring points [1]. Basketball was created by Dr. James Naismith, who at that time was a graduate student and instructor at Springfield, Massachusetts in 1891 [2]. Since then basketball has grown around the world until now. The United States is the center of world basketball, where there is the most prestigious basketball league, the National Basketball Association (NBA) [3]. There are 30 teams competing for the NBA title [4]. The 30 teams are grouped into 2 regions, namely eastern conference and western conference, each of which consists of 15 teams [5].

The NBA has very complete statistical data and can be accessed publicly on the NBA's official website. Statistical data is very useful in modern sports. Match data can be used for the preparation of appropriate training programs, strategy formulation, and player recruitment [6]. Yarrow and Kranke argue that the collection of statistical data analysis data can provide appropriate feedback for talent scouts, coaches and athletes in improving the performance of athletes and teams [7].

NBA statistics for the 2020-2021 season are always updated. The 2020-2021 NBA season is slightly behind its usual schedule every season. Apart from that, the format of the match has also changed. The NBA Board and the National Basketball Players Association, Tuesday local time approved the basketball league in America for the 2020-2021 season starting December 22 after previously discussed in detail. This prestigious basketball league will host 72 regular 
season matches. This number has decreased compared to the previous number which reached 82 matches [8].

A total of 30 teams competes for the NBA title. One of the teams involved is the New York Knicks. In the 2019-2020 NBA season, the New York Knicks are ranked 25th out of 30 teams competing [9]. The New York Knicks didn't even qualify for the Playoffs. In the 20202021 NBA season, the New York Knicks showed improved performance and entered the top 8 in the eastern conference. However, there is still a problem experienced by the New York Knicks, namely shooting problems. At the end of 2020, the New York Knicks was ranked 27th for field goal made [10], 15th for 3 pointers made, and 29th for 2 points percentage [11]. From these data, it can be assumed that the New York Knicks need a reliable shooter as a solution. However, the New York Knicks coach recruited the veteran point guard on February 8,2021 [12]. This decision is interesting to study through research.

The point guard is the player's position in basketball. Point guards usually have a shorter stature when compared to players in other positions. However, point guards must have good skills, especially dribbling, passing and leadership. It's not uncommon for point guards to be team captains. The next position is shooting guard. This position requires complete shooting skills, from three points shot, midrange shot, layup, and under basket [13]. From the explanation of the two positions, it is clear that the shooting guard has the duty and obligation to the shooting record of the team. The decisions taken by the New York Knicks coach are all the more interesting. The purpose of this study is to examine the decision of the New York Knicks coach who prefers to recruit point guards over shooting guards.

\section{Method}

The method used in this research is descriptive quantitative. The data used is secondary data obtained from the NBA's official website, namely the New York Knicks match data for the 2020-2021 season. To be precise, the data on the 10 games the NY Knicks played with at the start of the season and 10 games with the new point guard. What is observed in this research are 9 indicators games statistics. Those indicators are: data of 2 points attempt (2PA), 2 points made (2PM), 2 points percentage ( $2 \mathrm{P} \%), 3$ points attempt (3PA), 3 points made (3PM), 3 points percentage (3P\%), field goal made (FGM), field goal attempt (FGA), and field goal percentage (FG\%). In addition, data on the New York Knicks' victories and defeats will also be presented in 20 matches in the 2020-2021 season. The data were analyzed using descriptive statistics

\section{Results and Discussion}

The 2020-2021 NBA season started more backwards when compared to previous seasons. This is the impact of the pandemic. The 2020-2021 NBA season starts on December 22, 2020 and the first game of the New York Knicks is on December 23, 2020. These 10 games have not recruited a new point guard. Here is the data for the first 10 games of the New York Knicks in the 2020-2021 season based on 9 Indicators: 
Table 1. New York Knicks First 10 Games in 2020-2021 Season

\begin{tabular}{llllllllll}
\hline Games & 2PM & 2PA & 2P\% & 3PM & 3PA & 3P\% & FGM & FGA & FG\% \\
\hline 1 & 27 & 57 & 47.4 & 12 & 28 & 42.9 & 39 & 85 & 45.9 \\
2 & 24 & 54 & 44.4 & 8 & 29 & 27.6 & 32 & 83 & 38.6 \\
3 & 30 & 58 & 51.7 & 16 & 27 & 59.3 & 46 & 85 & 54.1 \\
4 & 20 & 54 & 37.0 & 14 & 25 & 56.0 & 34 & 79 & 43.0 \\
5 & 29 & 52 & 55.8 & 3 & 36 & 8.3 & 32 & 88 & 36.4 \\
6 & 30 & 56 & 53.6 & 12 & 27 & 44.4 & 42 & 83 & 50.6 \\
7 & 36 & 64 & 56.3 & 7 & 21 & 33.3 & 43 & 85 & 50.6 \\
8 & 37 & 65 & 56.9 & 8 & 22 & 36.4 & 45 & 87 & 51.7 \\
9 & 25 & 69 & 36.2 & 9 & 27 & 33.3 & 34 & 96 & 35.4 \\
10 & 26 & 53 & 49.1 & 6 & 21 & 28.6 & 32 & 74 & 43.2 \\
\hline$\Sigma$ & 284 & 582 & & 95 & 263 & & 379 & 845 & \\
mean & $\mathbf{2 8 . 4}$ & $\mathbf{5 8 . 2}$ & $\mathbf{4 8 . 8}$ & $\mathbf{9 . 5}$ & $\mathbf{2 6 . 3}$ & $\mathbf{3 6 . 1}$ & $\mathbf{3 7 . 9}$ & $\mathbf{8 4 . 5}$ & $\mathbf{4 4 . 9}$ \\
\hline
\end{tabular}

From table 1 it is known that the New York Knicks had an average of 2 points made of 28.4 with an accuracy of 48.8 percent. Meanwhile, an average of 3 points made is 9.5 with an accuracy of 36.1 percent. While overall, the average field goal made was 37.9 with an accuracy of 44.9 percent. The accuracy of 2 points, 3 points, and field goal is relatively low when compared to the top NBA teams. In the first 10 games, the New York Knicks experienced 5 wins and 5 defeats. If the New York Knicks want to qualify for the play offs, especially if they are chasing the NBA title, of course, it requires a reliable shooter or shooting guard who can contribute points of 2 points or 3 points with high accuracy.

However, the New York Knicks coach instead brought in a point guard who could be considered a senior player rather than bringing in a shooting guard. The point guard in the 2019-2020 NBA season played for the Detroit Pistons team. Its statistical record in the Detroit Pistons is 18.1 points per game, the average field goal made is 7.4 with an accuracy of $49 \%$, the average point score of 3 points is 0.9 with an accuracy of 30.6 percent [14]. The points per game are quite high, but three points made and the accuracy is low. Meanwhile, the problem faced by the New York Knicks is 3 points attempt and 3 points made. Right on February 8, 2021, the New York Knicks officially recruited the point guard. Table 2 shows the 10 first games with the new point guard.

Table 2. New York Knicks First 10 Games After a New Point Guard Joined

\begin{tabular}{llllllllll}
\hline Games & 2PM & 2PA & 2P\% & 3PM & 3PA & 3P\% & FGM & FGA & FG $\%$ \\
\hline 1 & 27 & 59 & 45.8 & 10 & 28 & 35.7 & 37 & 87 & 42.5 \\
2 & 38 & 74 & 51.4 & 6 & 24 & 25.0 & 44 & 98 & 44.9 \\
3 & 33 & 58 & 56.9 & 12 & 28 & 42.9 & 45 & 86 & 52.3 \\
4 & 25 & 49 & 51.0 & 17 & 34 & 50.0 & 42 & 83 & 50.6 \\
5 & 26 & 60 & 43.3 & 7 & 27 & 25.9 & 33 & 87 & 37.9 \\
6 & 27 & 60 & 45.0 & 6 & 18 & 33.3 & 33 & 78 & 42.3 \\
7 & 27 & 68 & 39.7 & 11 & 29 & 37.9 & 38 & 97 & 39.2 \\
8 & 32 & 51 & 62.7 & 19 & 37 & 51.4 & 51 & 88 & 58.0 \\
9 & 28 & 57 & 49.1 & 12 & 24 & 50.0 & 40 & 81 & 49.4 \\
10 & 31 & 60 & 51.7 & 13 & 26 & 50.0 & 44 & 86 & 51.2 \\
\hline$\Sigma$ & 294 & 596 & & 113 & 275 & & 407 & 871 & \\
mean & 29.4 & 59.6 & 49.3 & 11.3 & 27.5 & 41.1 & 40.7 & 87.1 & 46.7 \\
\hline
\end{tabular}


The inaugural match with a new point guard took place on February 9, 2021 against the Miami Heat and lost [15]. The point guard played for 20 minutes 20 seconds scoring 14 points. Pretty good contribution in the first game even though his team got a defeated. The following is data on $10 \mathrm{New}$ York Knicks games with the new point guard.

Based on table 2, it can be seen that 2 points made are 29.4 with an accuracy of 49.3 percent. Meanwhile, the average 3 points made was 11.3 with an accuracy of 41.1 percent. While overall, the average field goal made was 40.7 with an accuracy of 46.7 percent. All of these indicators have improved when compared to the first 10 games at the start of the season. In these 10 matches, the New York Knicks have won 7 and lost 3. For more details, see the following table.

Table 3. Data Comparison

\begin{tabular}{|c|c|c|c|c|c|c|c|c|c|}
\hline & $2 \mathrm{PM}$ & $2 \mathrm{PA}$ & $2 \mathrm{P} \%$ & 3PM & 3PA & $3 \mathrm{P} \%$ & FGM & FGA & FG\% \\
\hline \multicolumn{10}{|c|}{ New York Knicks First 10 Games in 2020-2021 Season } \\
\hline$\Sigma$ & 284 & 582 & & 95 & 263 & & 379 & 845 & \\
\hline mean & 28.4 & 58.2 & 48.8 & 9.5 & 26.3 & 36.1 & 37.9 & 84.5 & 44.9 \\
\hline \multicolumn{10}{|c|}{ New York Knicks First 10 Games After a New Point Guard Joined } \\
\hline$\Sigma$ & 294 & 596 & & 113 & 275 & & 407 & 871 & \\
\hline mean & 29.4 & 59.6 & 49.3 & 11.3 & 27.5 & 41.1 & 40.7 & 87.1 & 46.7 \\
\hline
\end{tabular}

It is clear that there has been an increase in 2 points made, 2 points attempted, 2 points percentage, 3 points made, 3 points attempted, 3 points percentage, goal made field, goal attempt field, and goal percentage field. From the comparison of these data, we cannot see the point guard's contribution to the score obtained by the New York Knicks. The following are the point guard statistics for the first 10 matches.

Table 4. Point Guard First 10 Games with New York Knicks Data

\begin{tabular}{llllllllllll}
\hline MP & FG & FGA & FG\% & 3P & 3PA & 3P\% & FT & FTA & FT\% & AST & PTS \\
\hline $20: 20$ & 5 & 9 & 55.6 & 2 & 3 & 66.7 & 2 & 2 & 100 & 3 & 14 \\
$19: 58$ & 7 & 11 & 63.6 & 0 & 1 & 0 & 0 & 0 & & 6 & 14 \\
$23: 37$ & 3 & 9 & 33.3 & 0 & 1 & 0 & 2 & 2 & 100 & 3 & 8 \\
$16: 33$ & 1 & 10 & 10 & 0 & 1 & 0 & 2 & 2 & 100 & 2 & 4 \\
$18: 44$ & 1 & 8 & 12.5 & 0 & 1 & 0 & 2 & 2 & 100 & 2 & 4 \\
$27: 10$ & 6 & 15 & 40 & 2 & 4 & 50 & 2 & 2 & 100 & 8 & 16 \\
$27: 35$ & 7 & 11 & 63.6 & 2 & 2 & 1 & 2 & 2 & 100 & 6 & 18 \\
$37: 42$ & 6 & 11 & 54.5 & 1 & 3 & 33.3 & 4 & 4 & 100 & 11 & 17 \\
$32: 09$ & 6 & 14 & 42.9 & 2 & 3 & 66.7 & 0 & 1 & 0 & 5 & 14 \\
$29: 06$ & 6 & 15 & 40 & 1 & 5 & 20 & 0 & 0 & & 1 & 13 \\
\hline$\Sigma$ & 48 & 113 & & 10 & 24 & & 16 & 17 & & 47 & 122 \\
mean & 4.8 & 11.3 & 42.5 & 1 & 2.4 & 41.7 & 2 & 1.7 & 94.1 & 4.7 & 12.2 \\
\hline
\end{tabular}

The point guard's record is quite good with an average of 12.2 points, 4.7 assists, $94.1 \%$ free throw accuracy, but the average field goal made is 4.8 with an accuracy of 42.5 percent and an average acquisition of 3 points 1 with an average of 3 points attempt 2.4 is still quite low even though the accuracy of 3 points is 41.7 percent. The point guard's performance is still below his record when he played at the Detroit Pistons last season. Indeed, adjustments are needed with the new team. This may be one of the performance factors that have not been 
maximized even though the coach has given quite a lot of minutes of play, namely 25 minutes 29 seconds.

Basically, the point guard's job is to organize attacks, disrupt the opponent's defense, and give the ball to players who have a big chance of scoring points. Although in certain teams the point guard can be a mainstay in scoring points. This depends on the player's capabilities, not solely based on position. From the data presented above, it cannot be concluded whether the New York Knicks coach's decision to recruit a point guard is not appropriate. This is because the 2020-2021 NBA season is still ongoing. The point guard's overall contribution to the team is inconclusive at this point. The data presentation above can be an early illustration of the New York Knicks' performance in the 2020-2021 season. The trend of the New York Knicks' performance increases and has the opportunity to qualify for the playoffs.

To answer research questions, further study is needed after the 2020-2021 NBA season is over. Not only seen from the match statistics for the New York Knicks and the point guard. But it also needs statistical analysis to determine the player's contribution to the New York Knicks. The analysis that can be used is the Bayesian linear regression model [16].

\section{Conclusion}

Whether correct or not the New York Knicks coach's decision to recruit the point guard cannot be analyzed at present. The 2020-2021 NBA season is still running. This initial stage is only to give an idea of the different statistics for the New York Knicks in 10 games without a new point guard and 10 games with a new point guard. Statistical data shows improvements in all aspects of shooting. However, the point guard's contribution cannot be analyzed yet. Complete data for the 2020-2021 NBA season is required. Further data collection and appropriate analysis will be carried out so that the objectives of this research can be achieved.

\section{References}

[1] International Basketball Federation (FIBA). Official Basketball Rules 2020. 2020;(October):98. Available from: http://www.fiba.basketball/documents/official-basketball-rules.pdf

[2] Cooper M-B. Where Basketball was Invented: The History of Basketball [Internet]. Springfield College. [cited 2021 Apr 19]. Available from: https://springfield.edu/where-basketball-wasinvented-the-birthplace-of-basketball

[3] Basket TF. Basketball Leagues [Internet]. The First Basket. 2021 [cited 2021 Apr 19]. Available from: https://www.thefirstbasket.com/basketball-leagues/

[4] ESPN. NBA Teams [Internet]. ESPN. 2021 [cited 2021 Apr 19]. Available from: https://www.espn.com/nba/teams

[5] ESPN. NBA Standings 2020-2021 [Internet]. ESPN. 2021 [cited 2021 Apr 19]. Available from: https://www.espn.com/nba/standings

[6] Bartra S. The Role of Data Analytics in Modern Day Sports. Responsible Anal Data Min Educ [Internet]. 2017;(April 2017):101-18. Available from: https://www.researchgate.net/publication/330578956_The_Role_of_Data_Analytics_in_Modern_D ay_Sports

[7] Kranke DY and M. The performativity of sports statistics: towards a research agenda. J Cult Econ [Internet]. 2016;9(5):445-57. Available from: https://www.tandfonline.com/doi/abs/10.1080/17530350.2016.1202856?journalCode=rjce20

[8] Kuncahyo B. NBA musim 2020-2021 dimulai 22 Desember dengan 72 pertandingan [Internet]. Antara News. 2020 [cited 2021 Apr 25]. Available from: 
https://www.antaranews.com/berita/1833112/nba-musim-2020-2021-dimulai-22-desember-dengan72-pertandingan

[9] NBA. NBA Advanced Stats [Internet]. NBA. 2020. Available from: https://www.nba.com/stats/teams/traditional/?sort=W_PCT\&dir=-1\&Season=2019-

20\&SeasonType $=$ Regular Season

[10] Team Rankings. NBA Team Field Goals Made per Game [Internet]. Team Ranking. 2020 [cited 2021 Apr 25]. Available from: https://www.teamrankings.com/nba/stat/field-goals-made-pergame?date $=2020-12-31$

[11] Team Rankings. NBA Team Two Point \% [Internet]. Team Ranking. 2020 [cited 2021 Apr 25]. Available from: https://www.teamrankings.com/nba/stat/two-point-pct

[12] Berman M. New York Knicks 'engaged in active talks' as bombshell Derrick Rose trade looms [Internet]. Fox Sports. 2021 [cited 2021 Apr 25]. Available from: https://www.foxsports.com.au/basketball/nba/nba-trade-news-2021-derrick-rose-new-york-knicksmove-from-detroit-pistons-tom-thibodeau/news-story/a7733ecce815d535f15c0273d5ed1413

[13] Coaches B for. Basketball Positions: Key Roles and Responsibilities (explained) [Internet]. Basketball for Coaches. [cited 2021 Apr 25]. Available from: https://www.basketballforcoaches.com/basketball-positions/

[14] NBA. Derrick Rose [Internet]. NBA. 2020 [cited 2021 Apr 25]. Available from: https://www.nba.com/stats/player/201565/

[15] Basketball Reference. 2020-2021 NBA Schedule and Results [Internet]. basketball-reference.com. 2021 [cited 2021 Apr 25]. Available from: https://www.basketballreference.com/leagues/NBA_2021_games-february.html

[16] Jensen SKD and ST. Estimating an NBA Player's Impact on His Team's Chances of Winning. De $\begin{array}{llll}\text { Gruyter } \quad \text { 2016;12(2). Available from: } & \text { Anet]. }\end{array}$ https://www.degruyter.com/document/doi/10.1515/jqas-2015-0027/html 